\title{
Correlatos Valorativos das Motivações para Responder sem Preconceito frente à Homoparentalidade
}

\author{
Alessandro Teixeira Režende \\ Ana Karla Silva Soares ${ }^{2}$ \\ Valdiney Veloso Gouveia ${ }^{1}$ \\ Maria Gabriela Costa Ribeiro' \\ Thiago Medeiros Cavalcanti ${ }^{1}$ \\ ${ }^{1}$ Universidade Federal da Paraíba, João Pessoa, PB \\ ${ }^{2}$ Universidade Federal do Mato Grosso do Sul, Campo Grande, MS
}

\begin{abstract}
Resumo
Esta pesquisa objetivou conhecer em que medida os valores humanos se relacionam com as motivações para responder sem preconceito frente à homoparentalidade, tomando como base a Teoria Funcionalista dos Valores Humanos. Contou-se com a participação de 235 estudantes universitários, com idades variando de 18 a 55 anos $(M=24,0, D P=6,82)$, a maioria do sexo feminino (57\%). Estes responderam à Escala de Motivações para Responder sem Preconceito frente à Homoparentalidade, o Questionário dos Valores Básicos e perguntas demográficas, sendo os dados coletados on-line. Realizaram-se regressões múltiplas, tendo os resultados indicado que as motivações internas para responder sem preconceito foram explicadas pelas subfunções experimentação, suprapessoal, interativa e normativa, enquanto que os valores normativos e de experimentação explicaram as motivações externas. Concluiu-se que os valores podem ser bons preditores das motivações para responder sem preconceito frente à homoparentalidade, principalmente os idealistas, reforçando que pessoas que se pautam por tais valores costumam ser menos preconceituosas.

Palavras-chave: valores humanos, preconceito, homoparentalidade, motivações
\end{abstract}

Value Correlates of Motivations to Respond without Prejudice to Homoparenthood

\begin{abstract}
This study aimed to know the value correlates of motivations to respond without prejudice to homoparenthood, taking into accounts the Functional Theory of Human Values. Participants were 235 undergraduate students with age ranging from 18 to 55 years old $(M=24.0, S D=6.82)$, mostly female $(57 \%)$. They answered the Motivation to Respond without Prejudice to Homoparenthood Scale, the Basic Values Survey and demographic questions, being the data collected online. Multiple regressions revealed that the internal motivations to respond without prejudice were predicted by excitement, suprapersonal, interactive and normative subfunctions. On other hand, normative and excitement values explained the external motivations. In conclusion, human values can be accurate predictors for motivations to respond without prejudice toward homoparenthood, mainly those idealists, reinforcing that people who are guided by these values tend to be less prejudiced.
\end{abstract}

Keywords: human values, prejudice, homoparenthood, motivations.

\section{Correlatos Valorativos de las Motivaciones para Responder sin Prejuicio hacia la Homoparentalidad}

\section{Resumen}

Esta investigación ha tenido como objetivo conocer en qué medida los valores humanos se correlacionan con motivaciones para responder sin prejuicio hacia la homoparentalidad, teniendo en cuenta la Teoría Funcionalista de los Valores Humanos. Los participantes han sido 235 estudiantes universitarios, con edad variando de 18 a 55 años $(M=24.0, D T=6.82)$, la mayoría mujeres (57\%). Estos contestaron a la Escala de Motivaciones para Responder sin Prejuicio hacia Homoparentalidad, el Cuestionario de los Valores Básicos y preguntas demográficas, siendo el estudio realizado online. Por medio de regresiones múltiples, se ha observado que las motivaciones internas para responder sin prejuicio fueron explicadas por las subfunciones experimentación, suprapersonal, interactiva y normativa, mientras que los valores normativos y de experimentación explicaron las motivaciones externas. Se concluyó que los valores humanos pueden ser buenos predictores de motivaciones para responder sin prejuicio hacia la homoparentalidad, principalmente aquellos idealistas, reforzando que las personas que priorizan estos valores suelen ser menos prejuiciosas.

Palabras-clave: valores humanos; prejuicio; homoparentalidad; motivaciones.

Por se tratar de um fenômeno enraizado nas relações humanas, o preconceito, ainda em meados de 1950, recebeu atenção de Gordon W. Allport, que escreveu
The nature of prejudice (Allport, 1954). A definição de preconceito oferecida por Allport merece destaque na medida em que o aborda não apenas como sentimentos 
de antipatia e crenças negativas voltadas a determinado grupo, mas como um conjunto de práticas e comportamentos discriminatórios que vão resultar em atitudes hostis e desfavoráveis, estando interligadas a um julgamento errôneo, precipitado e prematuro que pode ser expresso e direcionado a um grupo como um todo ou a seus membros específicos (Allport, 1954).

$\mathrm{Na}$ conjuntura atual, é recorrente pensar que o preconceito frente a grupos minoritários tenha diminuído ao longo do tempo, devido a aspectos relacionados à transformação dos contextos social, político e histórico. Destarte, constata-se que o mesmo segue existindo, porém sob uma forma de expressão nova, sendo denominado na literatura como preconceito sutil ou moderno (Gouveia, Fonsêca, Milfont, \& Fischer, 2011; Sears \& Henry, 2005).

Esse preconceito moderno é manifestado de maneira mais velada, o que acarreta em maior dificuldade de ser diretamente percebido, visto que assume um caráter implícito. Pereira, Torres, Pereira e Falcão (2011) defendem a existência de uma real diferença entre os preconceitos flagrante e sutil, argumentando que o primeiro é caracterizado por um conjunto de crenças e sentimentos negativos frente a determinado grupo que é tido como inferior aos demais, enquanto que o segundo constitui uma oposição às demandas e reivindicações do grupo que é objeto de preconceito, assumindo um posicionamento de que tais exigências são desnecessárias.

Em torno desse cenário, o preconceito tende a atingir diversos grupos minoritários (Formiga, Osmar, \& Vaamonde, 2015). Especificamente, quanto ao preconceito frente a homossexuais, durante a década de 1960, o termo "homofobia" já era empregado como sinônimo de atitudes e comportamentos ofensivos voltados para gays e lésbicas (Barrientos, Cárdenas, Gómez, \& Frías-Navarro, 2013; Cerqueira-Santos, Winter, Salles, Longo, \& Teodoro, 2007). Recentemente, o relatório do Grupo Gay da Bahia $(2015,2016)$ mostrou que os homossexuais têm sido vítimas de manifestações extremas de violência, resultando em casos de espancamentos e assassinatos.

A não conformidade à norma heterossexual é responsável pela construção de estereótipos hostis (e.g., anormal, doente mental), que leva a exclusão daqueles que não se adequam aos papéis tradicionais de gênero (Guerra, Scarpati, Duarte, Silva, \& Mota, 2014). Somado a isso, Souza e Pereira (2013) argumentam que tais estereótipos propiciam a construção de identidades sexuais que tornam as diferenças entre os sexos em algo natural e determinado, levando a institucionalização da heterossexualidade como uma norma social vigente.

Nessa conjuntura, surgem atitudes negativas e discriminatórias frente à orientação homossexual, fazendo com que as diferentes formas de preconceito dificultem o acesso da população de gays e lésbicas a direitos, como, por exemplo, a construção de uma família a partir da adoção (Cerqueira-Santos \& Santana, 2015). Tendo em conta os aspectos supracitados, considera-se oportuno discutir a homoparentalidade de maneira pormenorizada, o que se faz a seguir.

\section{Homoparentalidade}

A parentalidade exercida no âmbito de configurações familiares, formadas por pessoas do mesmo sexo, tem recebido a denominação de homoparentalidade. O termo é relativamente recente, tendo surgido no contexto francês, no final do século XX, remetendo à vontade de uma pessoa de orientação homossexual ser ou ter a intenção de ser pai ou mãe de uma criança. Desse modo, a adoção homoparental é caracterizada como uma modalidade na qual o casal adotante é formado por homossexuais ou por ao menos um indivíduo que se autodeclara homossexual (Cecílio, Scorsolini-Comin, \& Santos, 2013).

A partir de um levantamento acerca das atitudes da população portuguesa frente à homoparentalidade, Costa et al. (2013) verificaram diferenças em relação à legislação da adoção, em que países como Bélgica, Dinamarca, Holanda, Reino Unido e Suécia permitem a adoção por casais formados por dois homens ou duas mulheres. No que diz respeito ao contexto brasileiro, o Supremo Tribunal Federal (STF) aprovou em 2011 a conjugalidade homossexual, assegurando aos casais homossexuais a garantia de direitos, tais como o recebimento de pensão e a possibilidade de adoção. Em 2015, o mesmo tribunal ratificou o direito à adoção homoparental, bem como legitimou oficialmente os arranjos formados por pessoas do mesmo sexo (STF, 2015).

Pesquisas considerando adoção por gays e lésbicas têm ganhado espaço no âmbito acadêmico, sendo conduzidas em diversos contextos (Freires, 2015; Parreira, 2014; Kemper \& Reynaga, 2015). Costa et al. (2013), por exemplo, utilizando uma amostra de 993 indivíduos da população portuguesa, investigaram as atitudes frente à homoparentalidade. A partir disso, verificaram que, apesar da maioria dos participantes apresentar uma atitude favorável à homoparentalidade, seus resultados mostraram uma atitude mais positiva em relação ao casal formado por heterossexuais. Ademais, os participantes 
anteciparam mais problemas emocionais e sociais em crianças adotadas por casais homossexuais.

Em estudo semelhante, Cerqueira-Santos e Santana (2015) objetivaram investigar as crenças de 132 estudantes de direito e serviço social sobre a orientação sexual e adoção homoparental. Seus resultados indicaram uma correlação negativa entre concordância em adotar e preconceito, por um lado, e uma correlação positiva entre concordância em adotar e contato interpessoal com homossexuais, por outro. Baiocco e Laghi (2013) analisaram o valor da parentalidade e a percepção individual de competência parental em uma amostra italiana de mulheres lésbicas $(n=201)$, homens gays $(n=199)$ e heterossexuais (feminino $=314$ e masculino $=216)$. Seus resultados mostraram que lésbicas e gays apresentaram uma menor percepção de competência parental e menos confiança em receber apoio social.

Parreira (2014), por sua vez, comparou as atitudes frente à homoparentalidade entre estudantes portugueses e espanhóis. A autora delineou um estudo experimental no qual foram apresentados a 630 estudantes (272 portugueses e 358 espanhóis) vinhetas que continham situações-estímulo (adoção de uma criança por casais homoparentais e heteroparentais) e duas escalas que mensuravam as competências parentais e o desenvolvimento das crianças. Os resultados desse estudo indicaram que os estudantes que tiveram mais contato com pessoas que se identificavam como gays/ lésbicas/bissexuais revelaram atitudes menos preconceituosas em relação à homoparentalidade.

$\mathrm{Na}$ mesma direção, Freires (2015) investigou a aceitação e oposição à homoparentalidade a partir do preconceito sexual e dos valores humanos em uma amostra brasileira de 339 indivíduos da população geral. No que diz respeito às dimensões de preconceito sexual, verificou-se que o heteressexismo (aversão a gays e lésbicas e negação da discriminação) se correlacionaram negativamente com a aceitação homoparental por adoção. Quanto aos valores humanos, verificou-se que a subfunção normativa se correlacionou negativamente com aceitação homoparental e positivamente com oposição à homoparentalidade. Por outro lado, os valores de cunho mais humanitário (interativos e suprapessoais) apresentaram uma correlação positiva com aceitação da homoparentalidade.

Mediante os estudos supracitados, parece evidente que os discursos e os posicionamentos frente à homoparentalidade são afetados por fatores diversos, como o preconceito, a rejeição de contato social e os estereótipos negativos. Tendo em vista a minimização de tais consequências, há um interesse de estudiosos em conhecer os preditores envolvidos na aceitação e oposição da adoção por casais homossexuais. Dentre as variáveis estudadas, destacam-se as atitudes frente à união homossexual (Cody, Farr, McRoy, Ayers-Lopez, \& Ledesma, 2016; Kimberly \& Moore, 2015), o gênero (Kemper \& Reynaga, 2015), a raça (Tan, Jordan-Arthur, Garafano, \& Curran, 2016), o desenvolvimento cognitivo e sexual de crianças adotadas (Gato \& Fontaine, 2016; Gato \& Fontaine, 2013) e as crenças sobre homossexualidade e adoção homoparental (Cerqueira-Santos \& Santana, 2015).

No entanto, é possível que o preconceito frente à homoparentalidade possa variar também em função de outras características individuais ou mesmo de princípios-guias assumidos pelos indivíduos. Nesse âmbito, enquanto sistemas cognitivos que representam as necessidades humanas e exercem influência em comportamentos e atitudes, os valores humanos podem se configurar como relevantes. Esse construto foi utilizado, por exemplo, por Gouveia, Athayde, Soares, Araújo e Andrade (2012) para estudar as motivações externas e internas para responder sem preconceito frente a gays e lésbicas, além do estudo de Freires (2015) já mencionado. Portanto, procura-se a seguir abordar esse construto, tendo em conta a Teoria Funcionalista dos Valores Humanos.

\section{Valores Humanos}

Apesar de uma compreensão razoavelmente consensual acerca dos valores humanos, diferentes teóricos vêm buscando explicar seu conteúdo e estrutura (e.g., Inglehart, 1991; Rokeach, 1973; Schwartz, 1994). Considera-se nessa oportunidade uma teoria específica, denominada como Teoria Funcionalista dos Valores Humanos, que se configura como uma proposta parcimoniosa e integradora (Gouveia, Milfont, \& Guerra, 2014). Esta tem sido empregada para compreender atitudes e comportamentos sociais (Gouveia et al., 2011), considerando, por exemplo, o preconceito religioso (Aquino, Gouveia, Silva, \& Silva, 2013), o preconceito frente a gays e lésbicas (Gouveia et al., 2012) e as atitudes frente a homoparentalidade (Freires, 2015).

A Teoria Funcionalista dos Valores Humanos admite alguns pressupostos básicos, a saber: (1) assume a natureza benevolente do ser humano; (2) possui uma base motivacional, à medida que os valores expressam cognitivamente as necessidades humanas; (3) considera os valores como princípios-guia dos comportamentos, ou seja, são categorias que orientam as condutas dos 
indivíduos no meio social; (4) possuem um caráter terminal, uma vez que representam um propósito em si; e, por fim, (5) têm uma condição perene, entendendo-se que a história é cíclica, isto é, os valores são aproximadamente os mesmos em todas as culturas através do tempo, variando mais em razão de papéis sociais assumidos (Gouveia et al., 2014).

Gouveia (2013) postula que os valores humanos são conceituados segundo duas funções psicológicas principais: (1) eles servem como princípios-guia para os comportamentos das pessoas (tipo de orientação) e (2) expressam cognitivamente suas necessidades (tipo de motivador). A primeira função é representada por três tipos de orientação: pessoal, central e social, sendo a segunda composta por dois tipos de motivadores: materialista (pragmático) e idealista (humanitário).

O cruzamento das duas funções, isto é, tipo de orientação (social, central e pessoal) e tipo de motivador (materialista e humanitário), gera uma estrutura bidimensional 3 x 2, correspondendo aos eixos horizontal e vertical, respectivamente. Tais funções são distribuídas de forma equitativa nos critérios de orientação social (interativa e normativa), central (suprapessoal e existência) e pessoal (experimentação e realização) (Gouveia, 2013; Medeiros, Gouveia, Gusmão, Milfont, Fonseca, \& Aquino, 2012).

Teorias prévias que consideram os valores no plano individual têm sido úteis para caracterizar as prioridades que orientam os indivíduos no âmbito social, possibilitando conhecer tomadas de decisões e manifestações de atitudes (e.g., Rokeach, 1973; Ros, 2006; Schwartz, 1994). A Teoria Funcionalista dos Valores Humanos também tem se relevado útil, oferecendo uma compreensão, por exemplo, da manifestação do preconceito frente à homoparentalidade (Freires, 2015). Portanto, considerando o suporte empírico que essa teoria tem recebido (Gouveia, 2013; Medeiros et al., 2012), parece evidente seu potencial para explicar as motivações internas e externas para responder sem preconceito frente à homoparentalidade. Porém, antes de descrever os achados desta pesquisa, parece pertinente conhecer o que tem sido observado sobre a relação entre os valores e o preconceito.

\section{Correlatos Valorativos do Preconceito}

Considerando que os valores humanos guiam os comportamentos dos indivíduos no meio social (Gouveia, 2013), alguns estudos vêm dispendendo esforços para verificar a influência que os valores têm na manifestação do preconceito (e.g., Gouveia, Souza, Araújo,
Guerra, \& Sousa, 2006; Gouveia et al. 2012), buscando identificar os elementos que antecedem os sentimentos de antagonismo e repulsa voltados a determinados grupos minoritários.

Dessa forma, Gouveia, Souza, Araújo, Guerra e Sousa (2006) estudaram em que medida os valores humanos exercem influência nas motivações internas e externas para responder sem preconceito frente a negros. Considerando amostra de estudantes do ensino médio e universitários, esses autores observaram que os participantes que se orientavam pela motivação interna endossaram os valores suprapessoais, como maturidade $(r=0,17, p<0,01)$, beleza $(r=0,16, p<0,01)$ e conhecimento $(r=0,13, p<0,001)$. No que diz respeito à motivação externa, percebeu-se que os indivíduos que são motivados por razões externas para responder sem preconceito endossaram os valores de prestígio $(r=$ $0,19, p<0,01)$ e privacidade $(r=0,17, p<0,01)$.

Utilizando a Escala de Motivação para Responder sem Preconceito frente a Gays e Lésbicas, Gouveia et al. (2012) observaram que as subfunções suprapessoal $(r=-0,19, p<0,05)$ e normativa $(r=0,13, p<$ $0,05)$ se relacionaram com as motivações internas para responder sem preconceito frente a gays. Em relação às motivações externas, houve uma correlação positiva com a subfunção existência $(r=0,11, p<0,05)$ e negativa com a suprapessoal $(r=-0,10, p<0,05)$. Ao assumir as lésbicas como grupo-alvo, constatou-se que a motivação interna se correlacionou negativamente com a subfunção normativa $(r=-0,12, p<0,05)$, e as motivações externas o fizeram positivamente com as subfunções existência $(r=0,15, p<0,05)$ e normativa $(r=0,16, p<0,05)$.

Considerando uma amostra de estudantes do ensino médio de escola pública, Aquino, Gouveia, Silva e Silva (2013) buscaram conhecer em que medida os valores humanos influenciavam na direção do preconceito religioso. Seus resultados indicaram que as subfunções interativa $(r=-0,15, p<0,05)$, suprapessoal $(r=-0,18, p<0,05)$ e experimentação $(r=-0,33, p<$ $0,001)$ se correlacionaram com o preconceito religioso. Esses autores ressaltaram que a associação entre os valores das subfunções suprapessoal e existência com o preconceito corrobora os achados do estudo de Gouveia et al. (2006), podendo-se afirmar que os valores influenciam o preconceito.

A partir do previamente exposto, o presente estudo partiu da hipótese de que determinados valores podem promover (e.g., normativos) ou inibir (e.g., suprapessoais) o preconceito frente ao arranjo 
familiar formado por casais homossexuais, o que torna importante conhecer quais as magnitudes dessa associação, especificamente na expressão do preconceito frente à homoparentalidade. Nesse sentido, o presente estudo teve como objetivo conhecer em que medida os valores humanos se correlacionam (explicam) com as motivações para responder sem preconceito frente à homoparentalidade.

\section{Método}

\section{Participantes}

Participaram 235 estudantes universitários de João Pessoa (PB), os quais apresentaram idade média de 24 anos $(D P=6,82$; variando de 18 a 55 anos), sendo a maioria do sexo feminino (57\%), heterossexual $(73 \%)$, solteira $(84,7 \%)$ e católica $(35,7 \%)$. Tratou-se de uma amostra de conveniência (não probabilística), contando-se com aqueles que, quando solicitados, dispuseram-se a participar da pesquisa.

\section{Instrumentos}

Além de perguntas demográficas (como idade, sexo, orientação sexual e estado civil), os participantes responderam às medidas descritas a seguir:

Escala de Motivação para Responder sem Preconceito frente à Homoparentalidade (MRPH). Essa medida se baseia na escala originalmente elaborada por Plant e Devine (1998) para avaliar a motivação para responder sem preconceito frente a negros. É constituída por dez itens distribuídos equitativamente nos fatores motivação interna (e.g., Procuro agir de forma não preconceituosa em relação a Homoparentalidade porque isso é importante para mim) e externa (e.g., Tento agir de forma não preconceituosa em relação a Homoparentalidade para evitar que os outros me pressionem) para responder sem preconceito. Esses itens verificam em que medida as pessoas dão respostas não preconceituosas frente à homoparentalidade, sendo respondidos em escala de nove pontos, variando de 1 (discordo totalmente) a 9 (concordo totalmente).

\section{Questionário dos Valores Básicos (QVB).} Compreende 18 itens ou valores específicos, cobrindo seis subfunções valorativas (Gouveia, 2013): existência (estabilidade pessoal, sobrevivência e saúde), realização (êxito, poder e prestígio), normativa (obediência, religiosidade e tradição), suprapessoal (beleza, conhecimento e maturidade), interativa (afetividade, apoio social e convivência) e experimentação (emoção, prazer e sexual). Com o fim de respondê-lo, o participante deve indicar o grau de importância que cada valor tem como um princípio-guia em sua vida, utilizando escala de resposta de sete pontos, variando de 1 (Pouco importante) a 7 (Muito importante).

\section{Procedimento}

Os dados foram coletados on-line. Solicitou-se a participação das pessoas por meio de redes sociais e e-mail, garantindo-se o caráter anônimo e a natureza voluntária da participação, assegurando o direito de desistir do estudo sem quaisquer consequências. Todos assinaram o Termo de Consentimento Livre e Esclarecido, segundo recomendação da Resolução CNS 510/16, autorizando a utilização dos dados em produções acadêmicas. Este estudo contou com aprovação do Comitê de Ética em Pesquisa (CAAE: 30598714.1.0000.5302).

\section{Análise dos Dados}

Empregou-se o programa SPSS (versão 21), permitindo calcular estatísticas descritivas (medidas de tendência central, dispersão e frequência) para caracterizar os participantes do estudo; correlações $(r$ de Pearson) para estimar a associação entre as subfunções valorativas e as motivações para responder sem preconceito frente à homoparentalidade e, por fim, regressão múltipla (método stepwise) para conhecer o poder preditivo dos valores na explicação destas motivações.

\section{Resultados}

Inicialmente, optou-se por conhecer em que medida as subfunções valorativas se correlacionariam com os dois fatores de motivação para responder sem preconceito. Os resultados são apresentados na Tabela 1.

De acordo com a Tabela 1, a motivação interna se correlacionou mais fortemente com as subfunções experimentação $(r=0,22 ; p<0,001)$, suprapessoal $(r=$ $0,15 ; p<0,05)$, interativa $(r=0,21 ; p<0,001)$ e normativa $(r=-0,27 ; p<0,001)$. Considerando a motivação externa, verificou-se que esta se correlacionou com as subfunções experimentação $(r=0,16 ; p<0,05)$ e normativa $(r=0,22 ; p<0,001)$.

Visando identificar o poder preditivo das subfunções valorativas na explicação dos tipos de motivação para responder sem preconceito, foram efetuadas duas análises de regressão múltipla. Nessa oportunidade, a fim de evitar o efeito de multicolinearidade, optou-se pelo método de regressão stepwise. Especificamente, efetuaram-se duas análises tendo em conta cada um dos dois tipos de motivação (interna e externa) como 
Tabela 1.

Correlatos Valorativos do Preconceito frente à Homoparentalidade

\begin{tabular}{lcccc}
\hline \multirow{2}{*}{ Valores } & $\mathrm{M}(\mathrm{DP})$ & $\alpha$ & \multicolumn{2}{c}{ Tipos de motivação } \\
\cline { 4 - 4 } Experimentação & $4,99(1,10)$ & 0,61 & $0,22^{* *}$ & $0,16^{*}$ \\
Sexualidade & $4,96(1,45)$ & & 0,09 & 0,11 \\
Emoção & $4,49(1,62)$ & & $0,15^{*}$ & $0,14^{*}$ \\
Prazer & $5,55(1,30)$ & & $0,26^{* *}$ & 0,12 \\
Realização & $4,68(1,12)$ & 0,62 & 0,03 & 0,08 \\
Poder & $3,93(1,54)$ & & 0,01 & $-0,01$ \\
Exito & $5,80(1,22)$ & & $-0,01$ & 0,10 \\
Prestígio & $4,32(1,67)$ & & 0,06 & 0,09 \\
Existência & $6,17(0,93)$ & 0,62 & 0,01 & 0,07 \\
Estabilidade Pessoal & $5,91(1,23)$ & & 0,02 & 0,05 \\
Saúde & $6,11(1,32)$ & & $-0,05$ & 0,10 \\
Sobrevivência & $6,51(1,04)$ & & 0,06 & 0,02 \\
Suprapessoal & $5,83(0,95)$ & 0,64 & $0,15^{*}$ & 0,07 \\
Conhecimento & $6,02(1,28)$ & & 0,10 & 0,05 \\
Maturidade & $6,38(0,97)$ & & $0,15^{*}$ & 0,03 \\
Beleza & $5,10(1,45)$ & & 0,11 & 0,07 \\
Interativa & $5,73(1,04)$ & 0,62 & $0,21^{* *}$ & 0,09 \\
Apoio Social & $6,13(1,31)$ & & $0,24^{* *}$ & 0,07 \\
Afetividade & $6,09(1,28)$ & & 0,10 & 0,05 \\
Convivência & $4,97(1,53)$ & & $0,15^{*}$ & 0,08 \\
Normativa & $4,25(1,50)$ & 0,70 & $-0,27^{* *}$ & $0,22^{* *}$ \\
Religiosidade & $3,95(2,34)$ & & $-0,26^{* *}$ & $0,19 * *$ \\
Obediência & $5,34(1,52)$ & & $-0,06$ & $0,23^{* *}$ \\
Tradição & $3,48(1,75)$ & & & \\
\hline
\end{tabular}

Notas. $* p<0,05 ; * *<<0,001$

variável-critério, e os valores específicos e as subfunções valorativas como variáveis antecedentes (preditoras). Os resultados são apresentados na Tabela 2.

Quanto à motivação interna, foram identificados como principais preditores a subfunção interativa e os valores tradição, prazer e saúde, os quais explicaram conjuntamente $19 \%$ da variância total ( $\mathrm{R}^{2}$ ajustado). Ressalta-se a relevância do valor tradição $\left[\mathrm{R}^{2}\right.$ ajustado $=0,08 ; F(1,233)=22,11 ; p=0,001]$ como o mais importante do modelo, visto sua contribuição de $8 \%$ na explicação total da motivação para responder sem preconceito. No que se refere à motivação externa, os melhores preditores foram as subfunções normativa e de experimentação, que explicaram conjuntamente 7\% da variância total ( $R^{2}$ ajustado).

\section{Discussão}

Apesar de estudos anteriores (e.g., Aquino et al., 2013; Gouveia et al., 2006; Vasconcelos, Gouveia, Souza-Filho, Sousa, \& Jesus, 2004) já avaliarem correlatos valorativos do preconceito, não foram identificadas pesquisas que avaliassem, especificamente, o preconceito frente à homoparentalidade. Nessa conjuntura, o presente estudo buscou conhecer em que medida os valores humanos se associam com as motivações para 
Tabela 2.

Regressão Linear da Motivação (Interna e Externa), tendo os Valores como Preditores

\begin{tabular}{|c|c|c|c|c|c|c|c|}
\hline & Preditores & $\mathrm{R}$ & $\mathrm{R}^{2}$ & $\mathrm{~F}(\mathrm{gl})$ & $\mathrm{B}$ & Beta & $\mathrm{T}$ \\
\hline \multirow{4}{*}{ 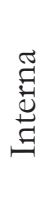 } & Tradição & 0,29 & 0,08 & $\mathrm{~F}(1,233)=22,11^{* *}$ & $-0,37$ & $-0,30$ & 4,90 \\
\hline & Interativa & 0,39 & 0,15 & $\mathrm{~F}(1,232)=19,11 * *$ & 0,53 & 0,25 & $-4,95$ \\
\hline & Prazer & 0,43 & 0,17 & $\mathrm{~F}(1,231)=7,81^{*}$ & 0,33 & 0,20 & 3,11 \\
\hline & Saúde & 0,45 & 0,19 & $\mathrm{~F}(1,230)=4,74^{*}$ & $-0,23$ & $-0,14$ & $-2,17$ \\
\hline \multirow{2}{*}{ 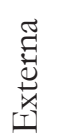 } & Normativa & 0,22 & 0,05 & $\mathrm{~F}(1,233)=11,73^{* *}$ & 0,30 & 0,22 & 3,48 \\
\hline & Experimentação & 0,27 & 0,07 & $F(1,232)=6,87$ & 0,31 & 0,17 & 2,62 \\
\hline
\end{tabular}

Notas. $* p<0,05 ; * * p<0,001$

responder sem preconceito frente à homoparentalidade, tomando como base a Teoria Funcionalista dos Valores Humanos (Gouveia, 2013; Soares, 2015; Gouveia, Milfont, Vione, \& Santos, 2015). Estima-se que esses objetivos tenham sido alcançados. De acordo com os resultados, verificou-se que as motivações internas para responder sem preconceito se correlacionaram mais fortemente com o conjunto de valores quando comparadas com as motivações externas, o que já tinha sido verificado no estudo de Gouveia et al. (2006).

Plant e Devine (1998) verificaram que as respostas das pessoas podem ser guiadas por interesses pessoais (motivadas internamente) ou orientadas por interesses sociais, isto é, evitando serem julgadas pelos demais (motivadas externamente). A partir disso, elencaram-se dois pressupostos fundamentais: (1) tanto a motivação interna quanto a externa afetam respostas não preconceituosas e preconceituosas frente a grupos minoritários, e, consequentemente, (2) é necessário conhecer tais motivações e seus correlatos a fim de identificar seu impacto em respostas dos indivíduos no meio social. Em torno dessa discussão, os estudos no âmbito do preconceito frente aos homossexuais vêm mostrando a influência da heteronormatividade na permanência dos padrões de gênero vigentes que consideram a união estável e a adoção de crianças por duas pessoas do mesmo sexo como algo que transgride aquilo que é tido como convencional pela sociedade (e.g., Freires, 2015; Formiga et al., 2015; Pereira, Torres, Pereira, \& Falcão, 2013; Pereira et al., 2011).

Os resultados do presente estudo corroboram essa perspectiva na medida em que foi observada uma correlação negativa entre a motivação interna e a subfunção normativa (obediência, religiosidade e tradição). Esse achado era esperado tendo em vista que pessoas motivadas internamente a responder sem preconceito possuem menos sentimentos negativos em relação a grupos minoritários, apresentando menos preocupações com avaliações sociais (Plant \& Devine, 1998), justificando a associação negativa entre a subfunção normativa e a motivação interna. Ressalta-se, ainda, que os indivíduos que pontuam alto na subfunção normativa priorizam as tradições e a preservação de padrões nos quais foram socializados, expressando uma repulsa a tudo que é diferente (Gouveia, 2013; Gouveia et al., 2014). Portanto, esses indivíduos endossam uma visão mais conservadora de experiências sexuais, reforçando a heteronormatividade (Guerra, Gouveia, Sousa, Lima, \& Freires, 2012).

Os achados apontaram também que as motivações externas se associaram positivamente com a subfunção normativa. Isso pode ser atribuído às características que definem os indivíduos guiados por tais motivações, uma vez que eles tendem a apresentar sentimentos mais negativos frente a grupos minoritários e, portanto, temem às avaliações sociais que podem ser feitas pelos demais, aderindo, assim, às normas antipreconceito. Nessa direção, as pessoas guiadas por tais valores expressam um comportamento sem preconceito, não devido às suas convicções internas, mas porque possuem crenças que endossam a ideia de que é socialmente errado emitir preconceito frente a homossexuais (Gouveia, 2016).

Resultados semelhantes foram encontrados no estudo de Gusmão et al. (2016), ao verificarem que os valores normativos foram fortes preditores da manifestação de homofobias flagrante e sutil. Destaca-se que a associação entre preconceito e valores normativos também foi encontrada no estudo de Gouveia et al. (2012), que, embora não tenham dado ênfase a homoparentalidade, verificaram que os valores de 
religiosidade e obediência apresentaram uma correlação negativa com a motivação interna, sendo esta positiva com a motivação externa para responder sem preconceito frente a gays e lésbicas. Pereira et al. (2013), por sua vez, mostraram que as representações sobre a homossexualidade que são baseadas em crenças religiosas e moralistas predizem o maior apoio a políticas discriminatórias contra o casamento e a adoção de crianças por casais homoafetivos.

Os resultados da presente pesquisa convergem com aqueles previamente encontrados, reforçando que pessoas que se pautam pela subfunção normativa se apegam mais às tradições, expressando maior repulsa ao diferente, procurando preservar os padrões da cultura vigente (Freires, 2015). Desse modo, elas tendem a demonstrar um olhar mais preconceituoso e estigmatizado das relações homoafetivas, sendo essa atitude expressa por meio de julgamentos morais em relação aos comportamentos dos homossexuais, a exemplo da união civil e da adoção (Pereira et al., 2013). Tais posicionamentos servem como barreira para que a sociedade tenha percepção mais positiva e naturalizada do processo de adoção por pessoas do mesmo sexo, mas também favorecem a manifestação de atos de violência (e.g., espancamento, assassinato) registrados na mídia (GGB, 2016).

Semelhante ao que foi encontrado na literatura, a subfunção suprapessoal se correlacionou com a motivação interna (Gouveia et al., 2012; Vasconcelos et al., 2004). Esses achados indicam que esse tipo de motivação é pautado por valores que não se limitam a dicotomia pessoal versus social, sendo mais idealista do que materialista no que concerne à promoção de atitudes menos preconceituosas. A subfunção em questão subsidia uma postura menos conservadora, de modo que a adoção de crianças por casais homossexuais não é percebida como uma ameaça à manutenção da estrutura social.

$\mathrm{Na}$ mesma direção do estudo de Gouveia et al. (2006), foi verificada uma correlação entre a subfunção interativa e a motivação interna. Indivíduos que priorizam essa subfunção dão ênfase à afetividade, convivência e manutenção das suas relações interpessoais harmônicas. Desse modo, eles tendem a apresentar um olhar menos preconceituoso e estereotipado das relações sexuais entre duas pessoas do mesmo sexo, não tratando essa questão como uma quebra de padrões tradicionais, mas formas alternativas de viver o amor e a parentalidade (Licciardello, Castiglione, \& Rampullo, 2011).
Concernente a essa ideia, Cerqueira-Santos e Santana (2015) verificaram uma correlação positiva entre o contato interpessoal, a amizade e a concordância com a adoção homoparental, demonstrando o efeito do contato e da convivência na quebra do preconceito (Cerqueira-Santos et al., 2007). Na mesma direção, Freires (2015) mostrou que a aceitação homoparental por adoção se correlacionou positivamente com disposição de proximidade e aceitação de contato; seus achados também evidenciaram que a oposição à adoção homoparental se correlacionou negativamente com disposição de proximidade e aceitação de contato.

Em geral, os achados desses estudos dão suporte à relação positiva entre a subfunção interativa e a motivação interna, mostrando que pessoas que prezam pela qualidade e manutenção de suas relações interpessoais não veem o contato e a convivência com homossexuais como algo desviante, demonstrando posicionamento positivo em relação à adoção homoafetiva e reconhecendo como legítima a família formada por pessoas do mesmo sexo (Cerqueira-Santos \& Santana, 2015; Gouveia, 2016). Nesse âmbito, é importante pensar no efeito do contato na quebra de preconceitos, uma vez que a convivência com esse grupo minoritário pode gerar mudança de estereótipos negativos relacionados aos pares homoafetivos, de modo que haja maior respeito e tolerância à diversidade da orientação sexual na sociedade (GGB, 2016).

Por fim, é necessário destacar que, independentemente do tipo de orientação, pessoas que se pautam por valores idealistas costumam ser menos preconceituosas. Isso pode ser explicado em razão do maior nível de abertura à mudança dessas pessoas, o que indica uma preocupação pelas mudanças sociais e o favorecimento da igualdade entre os indivíduos em sociedade, reconhecendo cada um como um ator social legítimo (Gouveia, 2013).

\section{Considerações Finais}

Mediante os achados apresentados, considera-se que o presente estudo tenha contribuído para a ampliação da literatura no âmbito da homoparentalidade, demonstrando o papel que podem ter os valores humanos como um construto que explica a variabilidade de motivações para responder sem preconceito. Entretanto, como todo empreendimento científico, o estudo em questão não está isento de limitações. Pode-se citar o uso exclusivo de medidas de autorrelato, que pode implicar em respostas enviesadas, uma vez que 
o respondente pode falsear suas respostas de maneira proposital, distanciando-se de seus reais comportamentos e valores (Soares et al., 2016).

Outra limitação potencial compreende a amostra do estudo, composta exclusivamente por estudantes universitários selecionados por conveniência. Isso limita a generalização dos achados para a população geral, mesmo a pessoense. Nesse sentido, recomenda-se a realização de estudos futuros que comprovem os resultados ora encontrados em amostras mais representativas e diversas, a exemplo de profissionais que atuem diretamente na área da adoção, como advogados e assistentes sociais (Cerqueira-Santos \& Santana, 2015). Resta, ainda, ter em conta uma medida de desejabilidade social (Soares et al., 2016); talvez esta possa mediar a relação entre os valores e as motivações para responder sem preconceito frente à homoparentalidade.

Apesar do anteriormente comentado, destaca-se que os achados foram majoritariamente na direção do que tem sido previamente observado na literatura (Gouveia et al., 2006; Gouveia et al., 2012), reforçando a adequação deste estudo. Contudo, não se descartam estudos futuros que tratem as motivações para responder sem preconceito frente a outras questões envolvendo o grupo-alvo, a exemplo da conjugalidade homossexual e de pessoas transexuais. Possivelmente, os valores poderão ter igualmente uma contribuição importante, restando estimá-la. Poder-se-á, igualmente, avaliar se as motivações frente a outros grupos minoritários (e.g., empregadas domésticas, usuários de drogas) também se pautam nos valores, comparando o poder explicativo desse construto quando comparado com a explicação da adoção homoparental, por exemplo.

Por último, apesar de se tratar de um estudo de natureza empírica, os resultados podem ser utilizados como base para propostas de intervenções voltadas para educação em valores, dando destaque para um processo que envolva a socialização de indivíduos em princípios que estejam fundamentados na promoção de atitudes não preconceituosas, sendo oportuno enfocar os valores de orientação igualitária, tais como as subfunções interativa e suprapessoal.

\section{Referências}

Allport, G. W. (1954). The historical background of modern social psychology. Em G. Lindzey (ed.). Handbook of social psychology (pp. 3-56). Reading, M.A: Addison-Wesley.
Aquino, T. A. A., Gouveia, V., da Silva, J. P., \& da Silva, D. M. (2013). Correlatos valorativos do preconceito religioso: Um estudo em uma escola pública estadual. Interação em Psicologia, 17, 259-269. Recuperado de https://revistas.ufpr.br/psicologia/ article/viewFile/27739/23885

Barrientos, J., Cárdenas, M., Gómez, F., \& Frías-Navarro, D. (2013). Assessing the Dimensionality of Beliefs About Children's Adjustment in SameSex Families Scale (BCASSFS) in Chile. Sexuality Research and Social Policy, 10, 43-51. doi: 10.1007/ s13178-012-0107-0

Cecílio, M. S., Scorsolini-Comin, F., \& Santos, M. A. D. (2013). Produção científica sobre adoção por casais homossexuais no contexto brasileiro. Estudos de Psicologia (Natal), 18, 507-516. doi: 10.1590/ S1413-294X2013000300011

Cerqueira-Santos, E., \& Santana, G. (2015). Adoção homoparental e preconceito: Crenças de estudantes de direito e serviço social. Temas em Psicologia, 23, 873-88. doi: 10.9788/TP2015.4-06

Cerqueira-Santos, E., Winter, F. D. S., Salles, L. A., Longo, J. L., \& Teodoro, M. L. (2007). Contato interpessoal e crenças sobre homossexualidade: Desenvolvimento de uma escala. Interação em Psicologia, 11, 221-229. doi: 10.5380/psi.v11i2.6639

Cody, P. A., Farr, R. H., McRoy, R. G., Ayers-Lopez, S. J., \& Ledesma, K. J. (2016). Youth perspectives on being adopted from foster care by lesbian and gay parents: Implications for families and adoption professionals. Adoption Quarterly, 1-21. doi: 10.1080/10926755.2016.1200702

Costa, P. A., Caldeira, S., Fernandes, I., Rita, C., Pereira, H., \& Leal, I. (2013). Atitudes da população portuguesa em relação à homoparentalidade. Psicologia: Reflexão e Crítica, 26, 790-798. doi: 10.1590/ S0102-79722013000400020

Formiga, N. S., Omar, A. G., \& Vaamonde, J. D. (2015). Atitudes frente aos grupos minoritários em brasileiros: Análise fatorial confirmatória e modelagem de equação estrutural. Encontro: Revista de Psicologia, 12, 71-84. Recuperado de http://www. pgsskroton.com.br/seer/index.php/renc/article/ view $/ 2547 / 2434$

Freires, L. A. (2015). Atitudes frente à homoparentalidade: Uma explicação a partir de variáveis explicitas e implícitas 
(Tese de doutorado). Departamento de Psicologia, Universidade Federal da Paraíba, João Pessoa, PB.

Gato, J., \& Fontaine, A. M. (2013). Anticipation of the sexual and gender development of children adopted by same-sex couples. International Journal of Psychology, 48, 244-253. doi: 10.1080/00207594.2011.645484

Gato, J., \& Fontaine, A.M. (2016). Attitudes toward adoption by same-sex couples: Effects of gender of the participant, sexual orientation of the couple, and gender of the child. Journal of LGBT Family Studies, 12, 46-67. doi: 10.1080/1550428X.2015.1049771

Gouveia, V. V. (2003). A natureza motivacional dos valores humanos: Evidências acerca de uma nova tipologia. Estudos de Psicologia (Natal), 8, 431-433. Recuperado de http://www.scielo.br/pdf/epsic/ v8n3/19965

Gouveia, V. V. (2013). Teoria funcionalista dos valores humanos: Fundamentos, aplicações e perspectivas. São Paulo: Caso do Psicólogo.

Gouveia, V. V. (2016). Introdução à Teoria Funcionalista dos Valores. In V. V. Gouveia (Ed.), Teoria Funcionalista dos Valores Humanos: Áreas de estudo e aplicações (pp. 13-27). São Paulo: Vetor.

Gouveia, V. V., Athayde, R. A. A., Soares, A. K. S., Araújo, R. D. C. R., \& de Andrade, J.M. (2012). Valores e motivações para responder sem preconceito frente a homossexuais. Psicologia em Estudo, 17, 215-225. Recuperado de http://s3.amazonaws. com/academia.edu.documents/46782263/ Valores_e_Motivao_para_Responder_sem_ Pre20160625-23232-15y0sn1.pdf?AWSAccessKe yId=AKIAIWOWYYGZ2Y53UL3A\&Expires=$1496086298 \&$ Signature $=$ FOUJLSQ0vwOagtw6a zaJ6gI3NQI\%3D\&response-content-disposition $=$ inline $\% 3 \mathrm{~B} \% 20$ filename $\% 3$ DValores_e_Motivacao_para_Responder_sem_P.pdf

Gouveia, V. V., Fonsêca, P. N., Milfont, T. L., \& Fischer, R. (2011). Valores humanos: Contribuições e perspectivas teóricas. Em C. V., Torres \& E. R., Neiva (Eds.), Psicologia social: Principais temas e vertentes (pp. 296-313). Porto Alegre, RS: ArtMed.

Gouveia, V. V., Milfont, T. L., \& Guerra, V. M. (2014). Functional theory of human values: Testing its content and structure hypotheses. Personality and Individual Differences, 60, 41-47. doi: 10.1016/j. paid.2013.12.012
Gouveia, V. V., Souza F, M. L. D., Araújo, A. G. T. D., Guerra, V. M., \& Sousa, D. F. M. D. (2006). Correlatos valorativos das motivações para responder sem preconceito. Psicologia: Reflexão e Crítica, 19, 422-432. Recuperado de http://www.redalyc.org/ $\mathrm{html} / 188 / 18819311 /$

Gouveia, V., Milfont, T. L., Vione, K. C., \& Santos, W. S. (2015). Guiding actions and expressing needs: On the psychological functions of values. Psykhe, 24, 1-14. doi: 10.7764/psykhe.24.2.884

Grupo Gay da Bahia - GGB (2015). Assassinato de homossexuais (LGBT) no Brasil: Relatório 2014/2015. Recuperado de http://homofobiamata.wordpress. $\mathrm{com} /$ estatisticas/ relatorios/.

Grupo Gay da Bahia. (2016). Assassinatos de LGBT no Brasil: Relatório 2016. Recuperado de https:// homofobiamata.files.wordpress.com/2017/01/ relatc3b3rio-2016-ps.pdf

Guerra, V. M., Gouveia, V. V., Sousa, D. M., Lima, T. J., \& Freires, L. A. (2012). Sexual liberalismconservatism: The effect of human values, gender, and previous sexual experience. Archives of Sexual Behavior, 41, 1027-1039. doi: 10.1007/ s10508-012-9936-4

Guerra, V. M., Scarpati, A. S., Duarte, C. N. B., Silva, C. V. D., \& Motta, T. A. (2014). Ser homem é: Adaptação da escala de concepções da masculinidade. Psico-USF, 19, 155-165. Recuperado de http:// www.redalyc.org/pdf/4010/401041441015.pdf

Gusmão, S. E. É., da Silva Nascimento, B., Gouveia, V. V., Ferreira Filho, L. G., da Costa, K. M. R., de Moura, H. M., \& Monteiro, R. P. (2016). Valores humanos e atitudes homofóbicas flagrante e sutil. Psico-USF, 21, 367-380. doi: 10.1590/1413-82712016210213

Inglehart, R. (1991). El cambio cultural en las sociedades industriales avanzadas. Madri: Siglo XXI.

Kemper, C. N., \& Reynaga, N. J. (2015). Social workers' attitudes towards lesbian, gay, bisexual and transgender adoptions. Masters dissertation. California State University. Recuperado de http:// scholarworks.lib.csusb.edu/cgi/viewcontent. cgi? article $=1180 \&$ context $=$ etd

Kimberly, C., \& Moore, A. (2015). Attitudes to practice: National Survey of Adoption Obstacles Faced by Gay and Lesbian Prospective Parents. Journal 
of Gay \& Lesbian Social Services, 27, 436-456. doi: 10.1080/10538720.2015.1085347

Licciardello, O., Castiglione, C., \& Rampullo, A. (2011). Intergroup contact, value system and the representation of homosexuality. Procedia Social and Behavioral Sciences, 30, 1467-1471. doi: 10.1016/j. sbspro.2011.10.284

Medeiros, E. D., Gouveia, V. V., Gusmão, S. E. É., Milfont, T. L., Fonseca, P. N., \& Aquino, T. A. A. (2012). Teoria funcionalista dos valores humanos: Evidências de sua adequação no contexto paraibano. Revista de Administração Mackenzie, 13, 18- 29. Recuperado de http://editorarevistas.mackenzie. br/index.php/RAM/article/viewFile/4174/3430

Parreira, A. M. T. (2014). Atitudes face à adoção homoparental: Um estudo comparativo entre estudantes do ensino superior portugueses e espanhóis (Dissertação de mestrado). Instituto universitário de Lisboa. Recuperado de https://repositorio.iscte-iul.pt/ handle/10071/9257

Pereira, C. R., Torres, A. R. R., Falcão, L., \& Pereira, A. S. (2013). O papel de representações sociais sobre a natureza da homossexualidade na oposição ao casamento civil e à adoção por famílias homoafetivas. Psicologia: Teoria e Pesquisa, 29, 79-89. Recuperado de http://www.ufrgs.br/seerpsicsoc/ojs2/index. $\mathrm{php} /$ seerpsicsoc/article/view/3819/2444

Pereira, C. R., Torres, A. R. R., Pereira, A., \& Falcão, L. (2011). Preconceito contra homossexuais e representações sociais da homossexualidade em seminaristas católicos e evangélicos. Psicologia: Teoria e Pesquisa, 27, 73-82. Recuperado de http:// www.scielo.br/pdf/ptp/v27n1/a10v27n1

Plant, E. A., \& Devine, P.G. (1998). Internal and external motivation to respond without prejudice. Journal of Personality and Social Psychology, 75, 811-832.

Rokeach, M. (1973). The nature of buman values. New York: Free Press.

Ros, M. (2006). Psicologia social dos valores humanos: Uma perspectiva histórica. Em M. Ros \& V. V. Gouveia (Eds.), Psicologia social dos valores humanos:
Desenvolvimentos teóricos, metodológicos e aplicados (pp. 23-53). São Paulo: Editora Senac.

Schwartz, S. H. (1994). Are there universal aspects in the structure and contents of human values? Journal of Social Issues, 50, 19-45. Recuperado de http:/ / dev.crs.org.pl:4444/ rid=1K6GFZBH9-255VHHF-GZ/Schwartz\%201994\%20\%20 Are $\% 20$ there $\% 20$ universal $\% 20$ aspects $\% 20$ in $\% 20$ the $\% 20$ content $\% 20$ of $\% 20$ human $\% 20$ values.pdf

Soares, A. K. S. (2015). Valores humanos no nivel individual e cultural: Um estudo pautado na teoria funcionalista (Tese de doutorado). Departamento de Psicologia, Universidade Federal da Paraíba, João Pessoa, PB.

Soares, A. K. S., Lopes, G. S., Rezende, A. T., Ribeiro, M. G. C., dos Santos, W. S., \& Gouveia, V. V. (2016). Escala de Deseabilidad Social Infantil (EDSI): Evidencias de validez factorial y fiabilidad. Avances en Psicología Latinoamericana, 34, 383-394. doi: 10.12804/apl34.2.2016.11

Souza, E. M., \& Pereira, S. J. N. (2013). Produção do heterossexismo e da heteronormatividade nas relações de trabalho: A discriminação de homossexuais por homossexuais. Revista de Administração Mackenzie, 14, 76-105. Recuperado de http:// search.proquest. com/openview/742d8619d9c8393aa8a645ac074d 8e74/1?pq-origsite $=$ gscholar\&cbl $=716404$

Tan, T. X., Jordan-Arthur, B., Garafano, J. S., \& Curran, L. (2016). Mental health trainees' explicit and implicit attitudes toward transracial adoptive families headed by lesbian, gay, and heterosexual couples. Journal of Homosexuality, 1-19. doi: 10.1080/00918369.2016.1236593

Vasconcelos, T. C., Gouveia, V. V., Souza Filho, M. L. D., Sousa, D. M. F. D., \& Jesus, G. R. D. (2004). Preconceito e intenção em manter contato social: Evidências acerca dos valores humanos. Psico-USF, 9, 147-154. Recuperado de http://www.scielo.br/ pdf/pusf/v9n2/v9n2a05

Recebido em: 07/03/2018

Reformulado em: 28/06/2018

Aprovado em: 05/07/2018 
Sobre os autores:

Alessandro Teixeira Rezende possui graduação em Psicologia (2016) pela Universidade Federal da Paraíba - UFPB. É mestre em Psicologia Social pela mesma instituição sob orientação do prof. doutor Valdiney Veloso Gouveia e colaborador do núcleo de Pesquisa Bases Normativas do Comportamento Social - BNCS. Seus interesses de pesquisa se centram nas áreas de Psicologia Social, Avaliação Psicológica e Psicometria.

ORCID: 0000-0002-5381-2155

E-mail:als_tx29@hotmail.com

Ana Karla Silva Soares é doutora em Psicologia Social pela Univerdidade Federal da Paraíba (UFPB), professora adjunta do curso de Psicologia da Universidade Federal do Mato Grosso do Sul (UFMS) e colaboradora do núcleo de pesquisa Bases Normativas do Comportamento Social (BNCS). Seus interesses de pesquisa se centram nas áreas de Fundamentos e Medidas em Psicologia, Análise de Sados e Psicologia Social.

ORCID: 0000-0001-5306-4073

E-mail: akssoares@gmail.com

Valdiney Veloso Gouveia é doutor em Psicologia Social pela Universidade Complutense de Madri (1998), professor titular do Departamento de Psicologia da Universidade Federal da Paraíba e bolsista de produtividade (1A) do CNPq. Seus interesses de pesquisa se centram nas áreas de Psicologia Social (estruturas sociais; indivíduos) e Avaliação Psicológica (construção e adaptação de escalas e testes).

ORCID: 0000-0003-2107-5848

E-mail:vvgouveia@gmail.com

Maria Gabriela Costa Ribeiro possui graduação em Psicologia pela Universidade Federal da Paraíba (2016). Fez mestrado no programa de pós graduação em Psicologia Social da mesma instituição e é integrante do núcleo de pesquisas Bases Normativas do Comportamento Social (BNCS), coordenado pelo professor Dr. Valdiney Veloso Gouveia. Alguns interesses em pesquisas são: Avaliação Psicológica, Psicologia Social e Psicologia Positiva.

ORCID: 0000-0001-6920-9070

E-mail:mariagabicr@gmail.com

Thiago Medeiros Cavalcanti possui Formação em Psicologia (2014) pela Universidade Federal da Paraíba (UFPB). É mestre e doutorando pelo Programa de Pós-Graduação em Psicologia Social da mesma instituição, onde encontra-se vinculado ao núcleo de pesquisa Bases Normativas do Comportamento Social (BNCS) coordenado pelo Prof. Dr. Valdiney Veloso Gouveia. Tem interesse em Psicologia Social, especificamente, valores e necessidades humanas.

ORCID: 0000-0002-4646-0761

E-mail: thiagomcavalcantii@gmail.com

Contato com os autores:

Alessandro Teixeira Rezende

Universidade Federal da Paraíba - Cidade Universitária

Campus 1, Bloco $\mathrm{C}-2^{\circ}$ andar, sala 01

Bairro Castelo Branco II, 58051-900

João Pessoa-PB, Brasil

E-mail:als_tx29@hotmail.com 